\title{
Effects of WC Particle Size and Co Content on the Graded Structure in Functionally Gradient WC-Co Composites
}

\author{
Yigao YUAN ${ }^{1, \mathrm{a}}$, Lanping $\mathrm{FU}^{1, \mathrm{~b}}$ and Jianpeng $\mathrm{LI}^{1, \mathrm{c}}$ \\ ${ }^{1}$ College of Mechanical Engineering, Donghua University, 201620, Shanghai, China

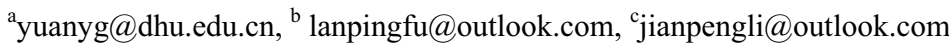

\begin{abstract}
Functionally gradient WC-Co composites having a Co depleted surface zone and not comprising the $\eta$ phase can be manufactured via carburizing process. During carburizing, besides carburizing process parameters, the microstructural parameters of WC-Co materials, such as WC grain size and Co content, also have significant influences on the formation of Co gradient structure. In this study, the effects of WC particle size and Co content on the gradient structure within gradient hardmetals have been studied, based on a series of carburizing experiments of WC-Co materials with different WC particle sizes and cobalt contents. The results show that both the thickness and the amplitude of the gradients within gradient WC-Co materials increase with increasing initial WC particle size and $\mathrm{Co}$ content of WC-Co alloys. The reason for this finding is discussed.
\end{abstract}

\section{Introduction}

Due to their unique microstructure and consequently superior combinations of wear resistance vs. fracture toughness, functionally gradient WC-Co composites with cobalt (Co) content increasing from surface to the interior of the bulk of the material have been the objective of intensive research in the hardmetal industry for a long time [1-3]. Many processes have been developed over the past decades to fabricate WC-Co cemented carbides with graded Co composition as described above. The most successful one is the so called Dual Property carbide (DP carbide) process [4, 5], which is based on the carburization of fully sintered hardmetals with the low carbon contents and containing uniformly distributed $\eta$-phase $\left(\mathrm{Co}_{3} \mathrm{~W}_{3} \mathrm{C}\right)$ at liquid phase sintering temperature. Although this technology allows the fabrication of gradient hardmetals with a very low Co content in the near surface layer, a significant disadvantage of these gradient hardmetals obtained by this approach is the presence of the very brittle core comprising much $\eta$-phase, which is detrimental to the mechanical properties of WC-Co materials.

In recent years, a novel process for manufacturing gradient WC-Co hardmetals has been developed by Fan et al $[6,7]$. In this process, the Co gradient is formed by heat treating conventional WC-Co in a carburizing atmosphere at a given temperature within the triple

* Corresponding author:yuanyg@dhu.edu.cn 
phase range in which that $\mathrm{WC}$, solid Co, and liquid Co coexist. Unlike in the DP carbide process, no brittle $\eta$-phase exists before the processing or forms during this process. Such a functionally gradient WC-Co material having a Co depleted surface zone and not comprising the $\eta$-phase, has been found to be able to offer excellent mechanical properties and thus superior engineering performance, compared with conventional homogeneous WC-Co materials [8].

In fabricating gradient hardmetals via carburizing process, the process parameters of carburizing heat treatment including temperature, carbon potential of the atmosphere, and time are critical factors that affect the formation of the Co gradient $[9,10]$. Besides, the microstructural parameters of WC-Co materials, such as WC grain size and Co content, also have significant effects on the formation of Co gradient structure in functionally graded WC-Co. However, the research on the influences of these microstructural parameters on graded structure, to the best of our knowledge, has until now not been widely reported in the open literature. In the present study, a series of carburizing experiments of WC-Co specimens with different WC particle sizes and Co contents were undertaken at different atmosphere conditions. The purpose of this work is to analyze the effects of WC particle size and Co content on Co gradient structure in $\mathrm{WC}-\mathrm{Co}$, and to provide an experiment basis for production of gradient WC-Co hardmetals.

\section{Experimental}

\subsection{Materials and sample preparation}

WC-Co powders with different WC particle sizes $(0.4 \mu \mathrm{m}$ and $0.8 \mu \mathrm{m})$ and cobalt contents $(6 \mathrm{wt} . \%$ and $10 \mathrm{wt} . \%)$ were selected for this study, which were used to produce three different kinds of WC-Co alloys labeled as 0406, 0806 and 0810 (where 04 and 08 denote WC particle size, while the 06 and 10 denote Co content). The WC-Co specimens with sub-stoichiometric carbon content, having no $\eta$-phase after conventional sintering but closing to the border with the $\eta$-phase formation according to the $\mathrm{WC}$-Co phase diagram, were prepared as follows: Tungsten (W) powder was added to the WC-Co mixed powder to reduce the total carbon content. The mixture of the powders was milled in alcohol for $48 \mathrm{~h}$ in a ball mill. The milled powder was dried at $95^{\circ} \mathrm{C}$ and then cold pressed at $200 \mathrm{MPa}$ into green compacts of $5 \times 6 \times 20 \mathrm{~mm}^{3}$ in dimensions. Finally, the green compacts were sintered in vacuum at liquid phase sintering temperatures for $1 \mathrm{~h}$.

The carburizing heat treatments of samples were conducted in atmosphere consisting of mixtures of methane $\left(\mathrm{CH}_{4}\right)$ and hydrogen $\left(\mathrm{H}_{2}\right)$ in a laboratory furnace with a graphite crucible of $20 \times 40 \times 20 \mathrm{~cm}^{3}$ in dimensions. The process parameters affecting the formation of Co gradient structure in WC-Co, namely, temperature, time, volume fraction of methane in carburizing atmosphere, and flow rate of mixed gases flowed into vacuum sintering furnace, were selected based on Ref.[9] and previous studies by the present authors [10,11]. Specially, to further verify the accuracy of experimental results, six experiments were performed on all samples under different carburizing conditions. The combinations of process parameters in the tests are given in Table 1. 
Table 1 Process Parameters Used During Carburizing Experiments

\begin{tabular}{|c|c|c|c|c|}
\hline \multirow{2}{*}{$\begin{array}{c}\text { Test } \\
\text { number }\end{array}$} & \multicolumn{4}{|c|}{ Process parameters of carburizing heat treatment } \\
\cline { 2 - 5 } & $\begin{array}{c}\text { Temperature, } \\
\left({ }^{\circ} \mathrm{C}\right)\end{array}$ & $\begin{array}{c}\text { Time, } \\
(\mathrm{min})\end{array}$ & $\begin{array}{c}\text { Volume fraction of methane, } \\
(\text { Vol.\%) }\end{array}$ & $\begin{array}{c}\text { Flow rate of mixed gases, } \\
(\mathrm{L} / \mathrm{min})\end{array}$ \\
\hline 1 & 1320 & 160 & 1.2 & 8 \\
\hline 2 & 1320 & 240 & 0.9 & 4 \\
\hline 3 & 1300 & 200 & 1.2 & 4 \\
\hline 4 & 1300 & 160 & 0.9 & 6 \\
\hline 5 & 1280 & 200 & 0.9 & 8 \\
\hline 6 & 1280 & 160 & 0.6 & 4 \\
\hline
\end{tabular}

\subsection{Microstructural characterization}

Measurements of Co content in functionally gradient WC-Co composites were examined as a function of depth perpendicular to the surface of polished cross-sections of test samples. The cobalt concentration profiles were measured using an energy dispersive spectroscopy (EDS) technique. Each data point of the Co composition is an averaged value obtained by scanning a $10 \times 60 \mu \mathrm{m}^{2}$ rectangular area that was parallel to the surface of the sample. The rectangular area for measurement was spaced at $10 \mu \mathrm{m}$ increments in the direction perpendicular to the original surface.

In this investigation, two measurable parameters extracted from the Co concentration profiles of each as-treated sample, i.e., amplitude of cobalt gradient and thickness of gradient zone, are used to quantitatively evaluate the Co gradient structure. The amplitude of cobalt gradient is defined as the difference between the nominal Co content and the lowest Co content as a fraction of the nominal content of the bulk. The thickness of the gradient zone is defined as distance from original surface to the position where the Co content reaches its nominal Co content as in the bulk of the specimen.

In addition, the magnetic properties of both the as-sintered and as-treated specimens, including relative magnetic saturation and coercivity, were measured in order to evaluate if there was any brittle $\eta$-phase in the microstructures, and to analyze $\mathrm{WC}$ grain growth during carburizing. The relative magnetic saturation was determined using a cobalt magnetism meter (ACoMT, China), and the coercivity measurements were carried out according to DIN ISO 3326 using a coercive force meter (YSK-IV, China).

\subsection{Results and Discussion}

The measurement results of the gradient structures and the magnetic properties of samples are listed in Table 2 . 
Table 2 The Measurement Results Of Gradient Structures And Magnetic Properties Of Samples

\begin{tabular}{|c|c|c|c|c|c|c|c|}
\hline \multirow{2}{*}{$\begin{array}{c}\text { Test } \\
\text { number }\end{array}$} & \multirow[b]{2}{*}{ Materials } & \multicolumn{2}{|c|}{ Gradient structure } & \multicolumn{2}{|c|}{$\begin{array}{c}\text { Relative magnetic } \\
\text { saturation, \% }\end{array}$} & \multicolumn{2}{|c|}{$\begin{array}{l}\text { Coercivity, } \\
\text { kA/m }\end{array}$} \\
\hline & & $\begin{array}{l}\text { Thickness } \\
\text { of gradient } \\
\text { zone, } \mu \mathrm{m}\end{array}$ & $\begin{array}{l}\text { Amplitude } \\
\text { of cobalt } \\
\text { gradient, \% }\end{array}$ & as-sintered & as-treated & as-sintered & as-treated \\
\hline \multirow{3}{*}{1} & 0410 & 385 & 15.8 & 76.6 & 79.9 & 28.68 & 27.06 \\
\hline & 0810 & 540 & 21.3 & 76.7 & 85.8 & 23.56 & 21.85 \\
\hline & 0806 & 300 & 13.5 & 76 & 85.3 & 23.83 & 23.3 \\
\hline \multirow{3}{*}{2} & 0410 & 412 & 25.2 & 76.6 & 80.5 & 28.64 & 26.47 \\
\hline & 0810 & 567 & 79.1 & 77 & 86.8 & 23.56 & 21.78 \\
\hline & 0806 & 369 & 52.5 & 75.5 & 81.7 & 23.48 & 23.31 \\
\hline \multirow{3}{*}{3} & 0410 & 376 & 47.3 & 76.4 & 79.6 & 28.55 & 27.59 \\
\hline & 0810 & 394 & 47.4 & 76 & 89.8 & 24.28 & 22.74 \\
\hline & 0806 & 165 & 20.2 & 76 & 84.5 & 23.81 & 23.44 \\
\hline \multirow{3}{*}{4} & 0410 & 276 & 26.1 & 76.6 & 78.8 & 28.73 & 27.51 \\
\hline & 0810 & 396 & 62.5 & 77.6 & 83.1 & 23.53 & 22.8 \\
\hline & 0806 & 247 & 13.1 & 76.8 & 80 & 23.71 & 23.6 \\
\hline \multirow{3}{*}{5} & 0410 & 257 & 37.2 & 76.1 & 79.1 & 28.75 & 27.77 \\
\hline & 0810 & 432 & 59.8 & 76 & 86.7 & 23.14 & 22.21 \\
\hline & 0806 & 371 & 15.0 & 76.3 & 86 & 23.49 & 23.46 \\
\hline \multirow{3}{*}{6} & 0410 & 136 & 21.2 & 75 & 77.2 & 28.83 & 27.91 \\
\hline & 0810 & 362 & 25.2 & 77.8 & 83.0 & 23.51 & 23.03 \\
\hline & 0806 & 166 & 16.3 & 76.6 & 80.3 & 23.56 & 23.33 \\
\hline
\end{tabular}

From Table 2, it can be seen clearly that both the thickness and the amplitude of the gradients within gradient WC-Co materials have a tendency to increase with increasing initial Co content (at fixed WC particle size) and WC particle size (at fixed Co content), even though the experiments are conducted under different atmospheric conditions. This suggests that higher initial Co contents and larger WC particle sizes in WC-Co materials are beneficial for obtaining greater thickness and amplitude of cobalt gradient during carburizing process.

The relative magnetic saturation is often used to assess the tungsten concentration in the cobalt binder and the overall carbon content of the WC-Co alloy, while the coercivity is used as an indirect assessment of WC grain size. In general, the coercivity decreases as the WC grain size increases, and at relative magnetic saturation below $75 \%$, the overall carbon content in the WC-Co material is low enough for $\eta$-phase to start being detected [12]. From the measurement results of the magnetic properties of all samples after and before treated, as shown in Table.2, it can be deduced that there is no $\eta$-phase existing in the microstructures, and the WC grains have a tendency to grow up after carburizing heat treatment. As the presence of free (uncombined) carbon cannot be detected by magnetic saturation measurements, the cross-section of the 0810 sample of test No.3 after treated, which has a maximum value of relative magnetic saturation $(89.8 \%)$, was thus examined by 
means of X-ray diffraction, the XRD examination did not reveal any free carbon in the material (as shown in Fig.1). Also, to further analyze WC grain growth during the heat treatment, WC grain sizes at the surface and in the interior of the 0410 sample of test No.3 after and before treated were measured based on SEM images of the microstructure using linear intercept method. The measurements of the mean grain sizes indicate that there is no significant difference throughout the specimen before carburizing, but the size of WC grains at the surface is obviously larger than that in the core of specimen after carburizing, as shown in Table 3.

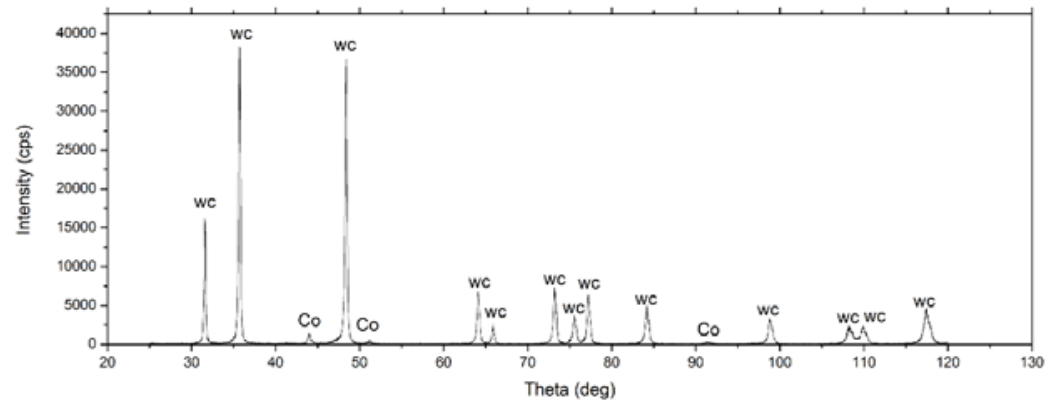

Fig.1 The X-ray diffraction spectra of the sample

Table 3 Measurement Results Of Wc Grain Sizes In Samples After And Before Treated

\begin{tabular}{|c|c|c|}
\hline \multirow{2}{*}{ Samples } & \multicolumn{2}{|c|}{ Average grain size of $\mathrm{WC}, \mu \mathrm{m}$} \\
\cline { 2 - 3 } & Surface & Core \\
\hline Before heat treatment & 0.379 & 0.384 \\
\hline After heat treatment & 0.493 & 0.402 \\
\hline
\end{tabular}

Fig. 2 shows the vertical sections of the ternary phase diagram of $\mathrm{W}-\mathrm{Co}-\mathrm{C}$ at $10 \mathrm{wt} . \%$ $\mathrm{Co}$ and 6 wt. \% Co [13]. According to the phase diagrams, WC, liquid Co, and solid Co coexist within the three-phase region located in the central region of the diagrams, and the amount of liquid Co phase increases with increasing carbon content at the expense of the solid Co phase. Before carburizing, as the $\mathrm{C}$ and Co contents are uniform everywhere in the material, hence the volume fraction of the liquid Co phase in the surface region and that in the core will equalize, and both of them are equal to zero. During carburizing, as a result of the surface carburization, the $\mathrm{C}$ content in the surface region increases, which causes the phase transformation of solid Co to liquid Co and an increase of volume fraction of liquid Co phase near the surface region. Thus, the liquid Co will migrate from the surface region with more liquid Co towards the inner region with less liquid $\mathrm{Co}$, and resulting in the formation of Co gradient with reduced Co content in the carburized surface region [9].

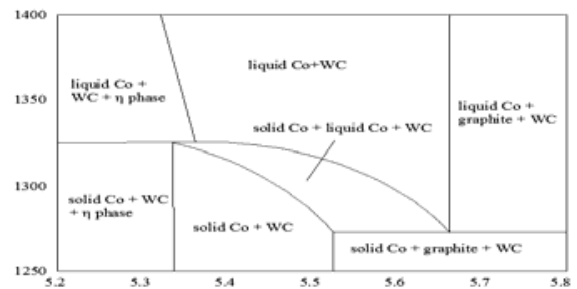

(a)

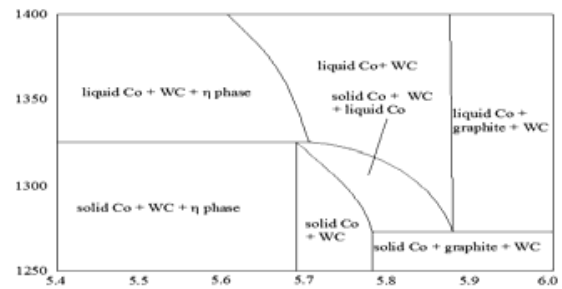

(b)

Fig.2 Vertical sections of the ternary phase diagram of W-Co-C at (a) $10 \mathrm{wt} . \%$ Co and (b) $6 \mathrm{wt} . \% \mathrm{Co}$ 
The driving force of the liquid Co phase migration described above is liquid migration pressure during carburizing heat treatments [14]. In a series of publications, Fan, Fang and coworkers $[15,16]$ systematically investigated the direction of liquid Co migration and the magnitude of liquid migration pressure by examining the Co distribution of bi-layered WC-Co specimens with the two layers having different compositions. They found that the liquid Co phase always migrates from a region with smaller liquid migration pressure toward a region with larger one within WC-Co, and the dependence of liquid migration pressure as a function of WC particle size and the volume fraction of liquid Co phase can be expressed as [15]:

$$
P_{m}=2048\left[(1 / u-1)^{1 / 3}-1.41 u\right] / d^{0.4}
$$

where $P_{\mathrm{m}}$ is the liquid migration pressure, $\mathrm{Pa} . u$ is volume fraction of liquid Co phase, and $d$ is $\mathrm{WC}$ particle size, $\mathrm{m}$.

According to Eq.(1), the liquid migration pressure, $P_{\mathrm{m}}$, will decrease with increasing the volume fraction of liquid Co phase, $u$, and WC particle sizes, $d$, at the same carburizing condition. As a result, for two WC-Co alloys of similar Co contents but different WC grain sizes, e.g. 0810 and 0410 alloys, the liquid migration pressure in surface region of 0810 alloy with coarser WC grains (average grain size of WC is $0.8 \mu \mathrm{m}$ ) is smaller than that of 0410 alloy with finer WC grains (average grain size of WC is $0.4 \mu \mathrm{m}$ ). Theoretically, the higher the liquid migration pressure, the stronger the absorbing force the WC-Co exerts on the external liquid Co. That is to say, the larger the difference of liquid migration pressure between the core and the surface region of WC-Co during carburizing, the easier the liquid Co migrates inwardly from the surface toward the interior of the material, and thus leading to a greater amplitude of the gradients. Compared with 0810 alloy, the difference of liquid migration pressure between the interior and the surface region of 0410 alloy may be smaller, due to its higher liquid migration pressure in surface region. Consequently, migration of liquid Co phase in 0410 alloy from the surface region toward the interior is more difficult and thus resulting in smaller amplitude of cobalt gradient in this alloy. Similarly, for two WC-Co alloys with the same WC grain size but different Co contents, e.g. 0810 and 0806 alloys, the liquid migration pressure in surface region of 0810 alloy with higher Co content ( 10 wt. \%Co) is smaller than that of 0806 alloy with lower Co content $(6$ wt. \%Co). As a result, the amplitude of cobalt gradient in the 0806 alloy is smaller than that in 0810 alloy after carburizing heat treatments. Based on the experimental results and the analysis as described above, it can be concluded that the difference of liquid migration pressure between the interior and the surface region of WC-Co alloys during carburizing process, may dominate the amplitude of cobalt gradients in the gradient WC-Co hardmetals, instead of other factors.

During carburizing heat treatments, carbon can diffuse only through the channels of Co phase in WC-Co. Therefore, the size of channels of carbon diffusion becomes a pivotal factor that affect the thickness of gradient zone in the gradient WC-Co hardmetals. The thicker the Co layers between two adjacent WC particles, the larger the size of channels of carbon diffusion inwardly from the surface into the interior of the WC-Co materials, correspondingly. The thickness of cobalt binder phase between two adjacent WC particles, i.e. Co mean free path, can be obtained by an empirical formula as follows [17]:

$$
\lambda=8.74 \times 10^{-2}\left(\frac{D f_{\mathrm{Co}}}{\left.1-f_{\mathrm{Co}}\right)}\right)^{0.79}
$$


where $\lambda$ and $D$ is the Co mean free path and average grain size of $\mathrm{WC}, \mathrm{m}$, respectively. $f_{\mathrm{Co}}$ is the volume fraction of Co phase in WC-Co.

According to Eq.(2), the value of Co mean free path will increase with increasing of the average grain size of WC ( at fixed Co content) and volume fraction of Co phase in WC-Co ( at fixed WC particle size). As a result, the size of channels of carbon diffusion of 0810 alloy is larger than that of 0410 alloy during carburizing. Similarly, the size of channels of carbon diffusion of 0806 alloy is smaller than that of 0810 alloy.

During carburizing process, a greater difference of carbon composition between the surface and the core of the specimen will drive carbon diffusion continuously from the surface into the interior of the WC-Co materials and an increasing of carbon content in Co phase of WC-Co. On the one hand, an increasing of carbon concentration in Co phase will cause the phase transformation of solid Co to liquid Co and subsequent migration of liquid Co. On the other hand, when the concentration of carbon atoms dissolved in liquid Co phase exceeds its maximum solubility at given temperature, excess carbon atoms may be combined with $\mathrm{W}$ atoms dissolved in liquid Co to form secondary WC phase. The secondary WC phase prefers to grow on the surface of the primary WC grains due to the requirement of the free energy, and thus leading to the coarsening of $\mathrm{WC}$ grains. The driving force for the coarsening of WC grains should be attributed to the Ostwald ripening [18]. The Ostwald ripening of WC proceeds at the expense of C and $\mathrm{W}$ from the liquid Co solution. Since there is a carbon concentration gradient in the liquid Co from the surface to interior, the Ostwald ripening rates are different in various areas. In the surface region, Ostwald ripening rate is fast due to higher $\mathrm{C}$ concentration and volume fraction of liquid Co phase, and resulting in larger WC grains size, as shown in Table 3. The coarsening of WC grains will not only decrease the concentration of $\mathrm{W}$ in the liquid Co and thus resulting in an increase of the relative magnetic saturation and a decrease of coercivity of WC-Co materials, but also block the diffusion channel and thus leading to difficult for a further diffusion of carbon. As the Co mean free paths of 0410 and 0806 alloys are smaller than that of 0810 alloy, channels of carbon diffusion of these alloys during carburizing are more easily to be blocked partially or entirely, and thus resulting in a rapid decreasing of carbon diffusion flux. As a result, the thickness of the gradient in the 0410 and 0806 alloys are smaller than that in 0810 alloy after carburizing heat treatments, respectively.

\section{Conclusions}

In this study, a series of carburizing experiments of WC-Co specimens with different WC particle sizes and cobalt contents were performed at different atmosphere conditions. Based on the measurement results of gradient structures and magnetic properties of samples, the effects of WC particle size and Co content on the formation of Co gradient structure in functionally graded WC-Co were analyzed. Under the condition of this study, the following conclusions were obtained:

1) After carburizing, both the thickness and the amplitude of the gradients within gradient $\mathrm{WC}-\mathrm{Co}$ materials increase with increasing initial Co content and $\mathrm{WC}$ particle size of WC-Co alloys.

2) The difference of liquid migration pressure between the interior and the surface region of WC-Co alloys during carburizing process may dominate the amplitude of cobalt gradients in the gradient WC-Co hardmetals.

3) The limited thickness of the cobalt gradient may attribute to the coarsening of WC grains on the surface of WC-Co materials. 


\section{Acknowledgement}

This work is supported by Shanghai Natural Science Foundation (No. 13ZR1401300).

\section{References}

1. Konyashin I, Hlawatschek S, Ries B, Lachmann F, Sologubenko A, Weirich T. A new approach to fabrication of gradient WC-Co hardmetals. Int J Refract Met Hard Mater., 28(2010): 228-37

2. Konyashin I, Ries B, Lachmann F., Fry AT. Gradient WC-Co hardmetals: Theory and practice. Int J Refract Met Hard Mater., 36(2013):10-21

3. Fang ZZ, Fan P, Guo J. Functionally graded cemented tungsten carbide with engineered hard surface and the method for making the same. U.S. Patent, US20110116963

4. Fischer U, Hartzell E, Akerman J. Cemented carbide body used preferably for rock drilling and mineral cutting. US patent no. 4743515; 1988.

5. Fischer U, Waldenstrom M, Hartzell T. Cemented carbide body with increased wear resistance. US patent no. 5856626(1999)

6. Fan P, Fang ZZ, Guo J. A review of liquid phase migration and methods for fabrication of functionally graded cemented tungsten carbide. Int J Refract Met Hard Mater., 36(2013): 2-9

7. Guo J, Fan P, Wang X, Fang ZZ. A novel approach for manufacturing functionally graded cemented tungsten carbide. Int J Powder Metall., 47(2011): 55-62.

8. Wang X, Hwang KS, Koopman M, Fang ZZ, Zhang LH. Mechanical properties and wear resistance of functionally graded WC-Co. Int J Refract Met Hard Mater., 36(2013):46-51

9. Guo J, Fang ZZ, Fan P, Wang X. Kinetics of the formation of metal binder gradient in WC-Co by carbon diffusion induced liquid migration. Acta Mater., 59(2011): 4719-31

10. Yuan YG, Ding JJ, Wang YK, Wang Q, Sun WQ, Bai JS. Optimization of process parameters for fabricating functionally gradient WC-Co composites. Int J Refract Met Hard Mater., 43(2014):109-14

11. Yuan YG, Ding JJ, Wang YK, Sun WQ. Fabrication of functionally gradient ultrafine-grained WC-Co composites. Appl Mech Mater., 423-426(2013): 885-9.

12. Love A, Luyckx S, Sacks N. Quantitative relationships between magnetic properties, microstructure and composition of WC-Co alloys. J Alloys Compd., 489(2010): 465-68

13. Mahale AE. Phase diagrams for ceramists, X. American Ceramic Society; 1994.

14. Fan P, Guo J, Fang ZZ, Prichard P. Design of cobalt gradient via controlling carbon content and WC grain size in liquid-phase-sintered WC-Co composite. Int J Refract Met Hard Mater., 27(2009):256-60.

15. Fan P, Guo J, Fang ZZ, Prichard P. Effects of liquid-phase composition on its migration during liquid-phase sintering of cemented carbide. Metall Mater Trans A. 40A (2009):1995-2006.

16. Fan P, Eso O, Fang ZZ, Sohn HY. Effect of WC particle size on Co distribution in liquid-phase-sintered functionally graded WC-Co composite. Int J Refract Met Hard Mater., 26(2008):98-105.

17. Liu SR. Microstructure parameters of WC-Co cemented carbide. T Mater Heat Treat., 26(2005):62-64

18. Liu Y, Wang HB, Long ZY, Liaw PK, Yang JG, Huang BY. Microstructural evolution and mechanical behaviors of graded cemented carbides. Mater Sci Eng A., 426(2006): $346-54$ 